\title{
Mental health financing challenges, opportunities and strategies in low- and middle-income countries: findings from the Emerald project - CORRIGENDUM
}

Dan Chisholm, Sumaiyah Docrat, Jibril Abdulmalik, Atalay Alem, Oye Gureje, Dristy Gurung, Charlotte Hanlon, Mark J. D. Jordans, Sheila Kangere, Fred Kigozi, James Mugisha, Shital Muke, Saheed Olayiwola, Rahul Shidhaye, Graham Thornicroft and Crick Lund

\section{Keywords}

Low and middle income countries; mental health; mental health systems; financing.

\section{Copyright and usage}

(c) The Royal College of Psychiatrists 2021. This is an Open Access article, distributed under the terms of the Creative Commons Attribution-NonCommercial-NoDerivatives licence (http://creativecommons.org/licenses/by-nc-nd/4.0/), which permits noncommercial reuse, distribution, and reproduction in any medium, provided the original work is unaltered and is properly cited. The written permission of Cambridge University Press must be obtained for commercial re-use or in order to create a derivative work.

https://doi.org/10.1192/bjo.2019.24, Published online by Cambridge University Press, 06 August 2019
The above mentioned article has been updated to correct website links to additional tools and resources provided by the Emerald Project.

\section{Reference}

Chisholm D, Docrat S, Abdulmalik J, Alem A, Gureje O, Gurung D, Hanlon C, Jordans M, Kangere S, Kigozi F, Mugisha J, Muke S, Olayiwola S, Shidhaye R, Thornicroft $\mathrm{G}$ and Lund C (2019). Mental health financing challenges, opportunities and strategies in low- and middle-income countries: Findings from the Emerald project. BJPSych Open, 5(5), E68. doi:10.1192/bjo.2019.24 